\title{
HISTOPATHOLOGICAL AUDIT OF APPENDECTOMY SPECIMEN IN A TERTIARY CARE CENTER.
}

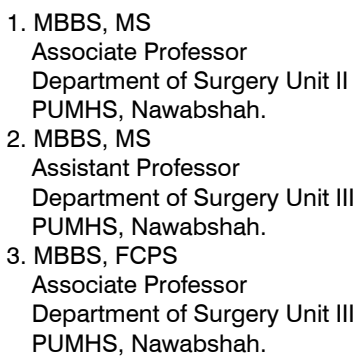

Correspondence Address: Dr. Sikandar-e-Azam Yousfani, Department of Surgery Unit-II Peoples University of Medical and Health Sciences, Nawabshah. coolsurgeonpk@gmail.com

Article received on: 26/03/2019

Accepted for publication: 25/06/2019

Received after proof reading: 30/09/2019

\begin{abstract}
Sikandar-e-Azam Yousfani ${ }^{1}$, Inayat Ali Zardari², Mashoque Ali Khoja ${ }^{3}$
ABSTRACT... Objectives: To evaluate the histopathological findings in appendectomy specimens and observe the negative appendectomy rate (NAR). Study Design: Observational study. Setting: Department of Surgery Unit III, Peoples University of Medical \& Health Sciences, Nawabshah. Period: January to December 2018. Material and Methods: 117 consecutive cases of appendectomy. All the demographic data and the clinicopathological details were recorded on a proforma designed for the study. The histopathological assessment was carried out in all cases. The ultrasound examination and CT scan was carried out in selected cases. The data collected was statistically analyzed and the results were tabulated. Results: During study period 117 appendectomies were performed. The mean age of patient was $27+9.4$ years, majority of patients $(53.8 \%)$ were females with female to male ratio of 1.2:1. The histopathological diagnosis was made in all cases and the results indicates that 105 cases having positive appendectomy and in $12(10.3 \%)$ cases the appendix was found histologically normal. Among 105 positive cases, $97(83 \%)$ were diagnosed as acute appendicitis, $2(1.7 \%)$ cases show fibrous obliteration and $6(5.1 \%)$ cases were having unusual pathologies. The cases having histological diagnosis of acute appendicitis includs acute mucosal appendicitis, acute suppurative appendicitis with or without periappendicitis and peritonitis, acute necrotizing appendicitis and perforated gangrenous appendicitis. The 6 cases of unusual pathologies includes 3 cases of granulomatous lesions and one case each of carcinoid tumor, mucinous cystadenoma and worm infestation. The ultrasound was performed in $48(41 \%)$ patients out of them 30 cases had positive findings on ultrasound examination were confirmed on histological examination and all 5 positive cases that were reported on CT scan were confirmed on histopathological examination. Conclusion: High rates of negative appendectomy in the female sex were observed, that can be reduced by the use of diagnostic imaging modalities specially ultrasound. The findings of abnormal pathologies on histopathological examination of the appendix suggest that histopathological analysis is necessary in all of the resected specimens.
\end{abstract}

Key words: Appendectomy, Histopathology, Negative Appendectomy Rate, Unusual Pathology.

Article Citation: Yousfani S, Zardari IA, Khoja MA. Histopathological audit of appendectomy specimen in a Tertiary Care Center. Professional Med J 2019; 26(10):17021705. DOI: 10.29309/TPMJ/2019.26.10.3449

\section{INTRODUCTION}

The vermiform appendix in humans is a rudimentary structure with no obvious function and some suggest that it serves as a storehouse for good bacteria, and also thought to be involved primarily in immune functions. ${ }^{1}$ Acute appendicitis is a global problem predominantly a disease of the Western world. It is particularly common in the United States and Europe. ${ }^{2}$ The difference has been explained on the basis of a dietary variance, the highest risk occurring when the diet is reduced in bulk, with diminished cellulose and a high protein intake. ${ }^{3}$
There is a wide belief that many and perhaps most cases of acute appendicitis develop as a result of obstruction, the resulting secretion under pressure impairing the resistance of the appendiceal mucosa to invasion by microorganisms, as shown by Wagensteen's pioneer studies in humans ${ }^{4}$. An obstructed appendix that was previously normal is more susceptible to infection than one affected by fibrous obliteration of the lumen. The most common cause of obstruction is a fecalith, but it may be a foreign body, a true calculus, a gallstone, a tumor of the cecum, or a primary tumor of the appendix. ${ }^{5-9}$ In children from the age of 10 years 
to young adults, diffuse lymphoid hyperplasia is another cause of obstruction. ${ }^{10}$ Nonobstructive appendicitis can be secondary to a generalized infection, usually of viral etiology. ${ }^{11}$

In the diagnosis of acute appendicitis and its complications, the role of imaging techniques particularly ultrasound, magnetic resonance imaging (MRI), and computed tomography (CT) scan are very important, as they can also give an alternative diagnosis. Reliable imaging modality in clinically suspected cases reduces the rate of negative appendectomy. Ultrasound studies should be the initial imaging technique especially for women of reproductive age group. In positive cases no further imaging investigation is needed but in suspected/inconclusive and negative cases further imaging work is required and these cases are diagnosed by the help of MRI, and CT scan is kept for selected cases, which is thought to be superior than ultra sound having sensitivity of 90 $100 \% .^{12,13}$

\section{METHODS}

This observational study was carried out in the department of Surgery Unit III, Peoples University of Medical \& Health Sciences, Nawabshah, during January to December 2018, on 117 consecutive cases of appendectomy. The only inclusion criteria was all male and female patients who were admitted in our hospital and operated for appendectomy regardless of their ages and cause. All the demographic data and the clinicopathological details were recorded on a proforma designed for the study. The histopathological assessment was carried out in all cases and cases without histopathological reports were not included in the study. Wherever necessary the ultrasound examination and CT

Histological Diagnosis

Normal Appendix

Acute Appendicitis

Fibrous Obliteration

Unusual Pathologies

Total scan was carried out in selected cases. The data collected was statistically analyzed and the results were tabulated.

\section{RESULTS}

During study period a total of 117 cases of appendectomies were evaluated. The mean age of patient was $27+9.4$ years, majority of patients (53.8\%) were females with female to male ratio of 1.2:1 (Table-I). The histopathological examination of appendectomy specimens was performed in all cases and the results indicates that 105 cases were revealing positive appendectomy (PA) and in $12(10.3 \%)$ cases the appendix was found histologically normal (Negative Appendectomy), among these 9 cases were found in female gender and 3 in male. Among 105 positive cases, 97 (83\%) were diagnosed as acute appendicitis, $2(1.7 \%)$ cases show fibrous obliteration and 6 (5.1\%) cases were having unusual pathologies. The cases having histological diagnosis of acute appendicitis includes acute mucosal appendicitis, acute suppurative appendicitis with or without periappendicitis and peritonitis, acute necrotizing appendicitis and perforated gangrenous appendicitis. Among 6 cases of unusual pathologies we diagnosed 3 cases of granulomatous lesions and one case each was diagnosed as carcinoid tumor, mucinous cystadenoma and worm infestation of Enterobius vermicularis (Table-II).

\begin{tabular}{|c|c|}
\hline Total No of Cases & 117 \\
\hline Female No(\%) & $63(53.8)$ \\
\hline Male No(\%) & $54(46.2)$ \\
\hline Female:Male & $1.2: 1$ \\
\hline Mean Age (years) & $27+9.4$ \\
\hline Imaging Studies & \\
\hline Ultrasound No(\%) & $48(41.0)$ \\
\hline CT Scan No(\%) & $05(04.3)$ \\
\hline Table-I. Demographic data \\
\hline
\end{tabular}

\begin{tabular}{|c|c|c|}
\hline \multicolumn{2}{|c|}{$\begin{array}{l}\text { No of Cases (\%) } \\
\text { No }\end{array}$} & Negative Appenaectomy \\
\hline & & $12(10.3)$ \\
\hline \multicolumn{2}{|c|}{97 (83.0) } & \\
\hline \multicolumn{2}{|c|}{$02(1.7)$} & \\
\hline \multirow{4}{*}{$06(5.1)$} & $03(2.6)$ & \\
\hline & $01(0.8)$ & \\
\hline & $01(0.8)$ & \\
\hline & $01(0.8)$ & \\
\hline \multicolumn{2}{|c|}{$105(89.7)$} & $12(10.3)$ \\
\hline
\end{tabular}

Table-Il. Histological diagnosis $(n=117)$ 
The ultrasound was performed in 48 (41\%) patients out of them 06 cases has negative findings, 12 cases were having inconclusive findings, and remaining 30 cases had positive findings on ultrasound examination. Among 06 negative cases 04 cases revealed positive histological findings and all 12 inconclusive cases also show positive histological findings, and 5 positive cases that were reported on CT scan were confirmed on histopathological examination.

\section{DISCUSSION}

Appendectomy is a common abdominal surgery throughout the world. ${ }^{14}$ For men and women the documented life time incidence of acute appendicitis is $8.6 \%$ and $6.7 \%$ respectively, and for appendectomy performed for various reasons is $12 \%$ and $25 \%$ for men and women respectively. ${ }^{15}$ The current study was conducted on 117 cases among them the majority (53.8\%) of cases were detected in female, confirming the results of previous studies. ${ }^{14,16}$

In current study we correlate the histopathological findings in appendectomy specimens with the clinical diagnosis of acute appendicitis and observe the negative appendectomy rate (NAR). Negative Appendicectomy Rate (NAR) is considered as a measure of quality traditionally in the management of acute appendicitis, and imaging modalities specially the ultrasound scan have contributed in keeping the NAR at a lower rates upto $1-3 \% .{ }^{17}$ It is justified historically that NAR serves to reduce the chances of perforation, as there is minimal morbidity and cost but extra and apparent clinical and financial load. ${ }^{18}$ Surgical excision of a normal appendix is not rare that bewray the patients to inevitable hazards of anesthesia and surgery, may be due to inaccurate clinical evaluation, availability of diagnostic facilities, which impedes the accuracy in the diagnosis. There are so many diseases clinically resembling the acute appendicitis. So, more skill and accuracy is needed for decreasing NAR and its complications. ${ }^{14,19}$ There is a huge difference in documented rates of NAR worldwide. In our study the NAR detected was $10.3 \%$ and was more common in female gender (9/12), these findings were comparable with other studies mentioning the NAR $9.5^{14}, 11.3^{20}, 12 \%{ }^{21}$, some show even high upto $40 \%$ in women of reproductive age group. ${ }^{22}$

We detect $5.1 \%$ unusual pathologies in our study consisting of 3 cases of granulomatous lesions and one case each was diagnosed as carcinoid tumor, mucinous cystadenoma and worm infestation. Different studies throughout the world detected various benign and malignant unusual pathology in resected appendix with varying frequency consistent with our study, supporting the value of routine histopathological examination of resected appendix. ${ }^{18,23,24,25}$

\section{CONCLUSION}

We observed high rates of negative appendectomy in the female sex that can be reduced by the use of diagnostic imaging modalities specially ultrasound. The findings of abnormal pathologies on histopathological examination of the appendix suggest that histopathological analysis is necessary in all of the resected specimens.

\section{Copyright $@ 25$ June, 2019.}

\section{REFERENCES}

1. Upadhayay KK. What is the function of appendix in our body. Quora. Oct 27, 2017. Available from; https:// www.quora.com.

2. Ferris M, Quan S, Kaplan B, Molodecky N, Ball C, Chernoff $G$, et all. The global incidence of appendicitis: A systemic review of population-based studies. Ann Surg. 2017; 266(2):237-41.

3. Naaeder SB, Archampong EQ. Acute appendicitis and dietary fiber intake. West Afric J Med. 1998; 17(4):2647.

4. Wangensteen $\mathrm{OH}$, Dennis $\mathrm{C}$. Experimental proof of the obstructive origin of appendicitis in man. Ann Surg. 1939; 110:629-47.

5. Bizer LS. Acute appendicitis is rarely the initial presentation of cecal cancer in an elderly patient. $J$ Surg Oncol. 1993; 54:45-6.

6. Forbes GB, Lloyd-Davies RW. Calculous disease of the vermiform appendix. Gut.1966; 7:583-92.

7. Nathans AA, Merenstein H, Brown SS: Lymphoid hyperplasia of the appendix. Pediatrics. 1995; 12:51624. 
8. Peltokallio P. Acute appendicitis associated with carcinoma of the colon. Dis Colon Rectum. 1966; 9:453-6.

9. Zarabi M, LaBach JP. Ganglioneuroma causing acute appendicitis. Hum Pathol. 1982; 13:1143-6.

10. Luckmann R, Davis P. The epidemiology of acute appendicitis in California. Racial, gender, and seasonal variation. Epidemiology. 1991; 2:323-30.

11. Reif RM. Viral appendicitis. Hum Pathol. 1981; 12:1936.

12. Zoarets I, Poluksht N, Halevy A. Does selective use of computed tomography scan reduce the rate of "white" (negative) appendectomy? Isr Med Assoc J. 2014; 16:335-7.

13. Debnath J, George RA, Ravikumar R. Imaging in acute appendicitis: What when and why. Med J Armed Forces India. 2017; 73(1):74-9.

14. Alhamdani YF, Rizk HA, Algethami MR, Algarawi AM, Albadawi RH, Faqih SN, et al. Negative Appendectomy Rate and risk factors that influence improper diagnosis at King Abdulaziz University Hospital. Mater Sociomed. 2018 Oct; 30(3): 215-20.

15. Flum DR, Koepsell T. The clinical and economical correlates of misdiagnosed appendicitis: Nationwide analysis. Arch Surg. 2002; 137(7):799-804.

16. Jahan B, Najeeb S, Shaikh AW. Acute appendicitis, correlating histopathological findings with clinical - is histopathology needed for all? PJMHS. 2016; 10(1):118-21.

17. Raja AS, Wright C, Sodickson AD, Zane RD, Schiff GD, Hanson $\mathrm{R}$, et al. Negative appendectomy rate in the era of CT: An 18-year perspective. Radiology. 2010; 256(2): 460-65.
18. Lu Y, Friedlander S, Lee SL. Negative appendectomy: Clinical and economic implications. Am Surg. 2016; 82(10):1018-22.

19. Joshi MK, Joshi R, Alam SE, Agarwal S, Kumar S. Negative appendectomy: An audit of residentperformed surgery. How can its incidence be minimized? Indian J Surg. 2015; 77(Suppl 3): 913-7.

20. Omiyale AO, Adjepong S. Histopathological correlations of appendectomies: A clinical audit of a single center. Ann Transl Med. 2015 Jun; 3(9): 119. Doi:10.3978/j.issn.2305-5839.2015.05.02.

21. Papes D, Srsen MS, AntabakA, Sjekavical I, Luetic T. What is the acceptable rate of negative appendectomy? Comment of the added value of imaging within the dutch national diagnostic appendicitis guideline Do we forget our clinical eye? Dig Surg. 2015; 32:1812.

22. Lewis FR, Holcroft JW, Boey J, Dunphy E. Appendicitis. A critical review of diagnosis and treatment in 1,000 cases. Arch Surg. 1975; 110(5):677-84

23. Dincel O, Goksu M, Turk BA, Pehlivanoglu B, Isler S. Incidental findings in routine histopathological examination of appendectomy specimens; Retrospective analysis of 1970 patients. Indian $\mathrm{J}$ Surg. 2018; 80(1): 48- 53.

24. Unver N, Coban G, Arici DS, Buyukpinarbasili N, Gucin $\mathrm{Z}$, Malya FU, et al. Unusual histopathological findings in appendectomy specimens: $A$ retrospective analysis of 2074 cases. Int J Surg Pathol. 2019; 27 (2): 142-6.

25. Yabanoglu H, Caliskan K, Aytac HO, Turk E, Karagulle E, Kayaselcuk F, et al. Unusual findings in appendectomy specimens of adults: Retrospective analyses of 1466 patients and a review of literature. Iran Red Crescent Med J 2014; 16(2):e12931.

\begin{tabular}{|c|l|l|l|}
\hline \multicolumn{3}{|c|}{ AUTHORSHIP AND CONTRIBUTION DECLARATION } \\
\hline Sr. \# & \multicolumn{1}{|c|}{ Author-s Full Name } & \multicolumn{1}{|c|}{ Contribution to the paper } & Author's Signature \\
\hline 1 & $\begin{array}{l}\text { Sikandar-e-Azam } \\
\text { Yousfani } \\
\text { Inayat Ali Zardari }\end{array}$ & $\begin{array}{l}\text { Concept \& Design of study, } \\
\text { Final approval of version. } \\
\text { Drafting. }\end{array}$ \\
\hline 3 & Mashoque Ali Khoja & $\begin{array}{l}\text { Data analysis, Revisiting } \\
\text { critically. }\end{array}$ \\
\hline
\end{tabular}

